\title{
A EDUCAÇÃO NOS ESTABELECIMENTOS PRISIONAIS
}

\author{
Nádia Lopes* \& Bravo Nico** \\ *Doutoranda do Programa de Doutoramento em Ciências da Educação da Universidade de Évora. \\ nadiafclopes@gmail.com; **: Departamento de Pedagogia e Educação da Escola de Ciências Sociais \\ da Universidade de Évora e CIEP-Centro de Investigação em Educação e Psicologia. jbn@uevora.pt
}

\begin{abstract}
Resumo
Apesar de todos querermos viver num mundo sem qualquer tipo de criminalidade, é extremamente utópico pensar que tal seja possível. Isto, porque é improvável que todos os indivíduos consigam viver e conviver sem incumprir alguma das normas que visam a salutar convivência na sociedade. Este incumprimento poderá levar os infratores a ficarem sujeitos a penas e/ou medidas de privação de liberdade.

Dependendo da tipificação do crime, poderão existir alternativas à reclusão, como, por exemplo, a vigilância eletrónica. Contudo, na maioria dos casos, o incumprimento resulta numa privação de liberdade, com espaço e tempo bem definidos. Esta medida é, ainda hoje, compreendida como sendo punitiva, quando, na realidade, pretende-se que ela seja corretiva. Assim, o tempo em que o indivíduo se encontra sujeito a medidas de privação de liberdade não pode ser encarado como ócio, mas sim aproveitado para auxiliá-lo a (re)adquirir competências que permitam a sua reintegração, de forma plena, aquando do regresso à sociedade.

Não se pode esquecer que, quando em situação de reclusão, o indivíduo apenas perde, temporariamente, o direito à liberdade, mantendo todos os outros direitos. Considerando este pressuposto, assim como a importância da educação na integração do Homem na sociedade, foi realizada uma investigação sobre as ofertas educativas, no âmbito da educação (formal, não formal e informal) no interior de três estabelecimentos prisionais, EP, do Sistema Judicial de Évora.

Considerando que a educação resulta de um processo de interação entre o objeto e o sujeito, pretende-se que esta seja capaz de auxiliar o sujeito a desenvolver o espírito crítico, assim como refletir sobre o mundo que o rodeia. Reconhecendo a educação como a "arma" para a construção de um "novo" indivíduo, os EP desenvolvem atividades que auxiliam o recluso a adquirir competências, considerando o seu percurso individual.
\end{abstract}

Palavras-chave: educação; estabelecimento prisional; reclusão; reintegração.

\section{INTRODUÇÃO}

O processo de reclusão pretende afastar da sociedade, temporariamente, o indivíduo que cometeu algum crime sobre a mesma, com o objetivo de protegê-la. Contudo, esta medida é encarada como uma punição, para o indivíduo infrator, quando, na realidade deveria servir para (re)educá-lo. O tempo de privação de liberdade deveria ser usado 
para fornecer ao recluso "ferramentas" que o auxiliassem no retorno à sociedade, impedindo-o de retomar a prática do crime.

No entanto, para que o retorno eficaz à sociedade possa ser uma realidade, é necessário garantir que o recluso consiga (re)adquirir algumas competências. Por um lado, pretende-se que o indivíduo consiga ser autónomo, financeira e socialmente, por outro, que seja capaz de ter uma atitude crítica e positiva sobre o meio na qual se encontra inserido.

Contudo, para que as competências de autonomia, espírito crítico, responsabilidade, saber estar, empatia, entre outras, que permitem a salutar convivência em sociedade sejam adquiridas, é necessário que o recluso tenha alguma orientação.

A (re)aprendizagem das competências, anteriormente referidas, realiza-se por meio da educação e, resultando esta de um processo de interação, é fundamental o contributo dos diversos agentes que desempenham funções no interior dos EP. Pretende-se que estes agentes se encontrem "abertos" e sensíveis à necessidade de formação dos reclusos, para que possam auxiliá-los no desenvolvimento destas competências.

No que aos responsáveis pelos EP diz respeito, os mesmos encontram-se consciencializados para a importância de educar/formar o seu público e, por esse motivo, promovem, através dos seus agentes mas também de voluntários, diversas atividades no âmbito da educação, formal e não formal.

Além dos baixos níveis de escolaridade (PORDATA, 2009), os reclusos também possuem níveis reduzidos de qualificação profissional, o que contribui para situações precárias, tanto a nível financeiro como social. Esta precariedade faz com que os reclusos pertençam a uma "franja" da sociedade que é muitas vezes marginalizada, pela mesma. Assim sendo, a educação poderá auxiliar a inverter esta situação.

No âmbito da educação formal, que essencialmente visa a certificação, destacam-se dois aspetos:

a) a qualificação escolar, de forma a aumentar o nível de escolaridade;

b) a certificação profissional, para que o recluso seja capaz de adquirir e/ou desenvolver competências que lhe permitam desempenhar uma atividade laboral, aquando do seu regresso à sociedade.

Para além da educação formal e numa perspetiva de desenvolvimento global do indivíduo, recorre-se à educação não formal. Esta atua ao nível sociocultural, com o objetivo de ajudar o recluso a desenvolver o sentido ético e estético, assim como proporcionar bem-estar físico, psíquico e emocional, para que a relação com os outros seja melhorada, mas também para aumentar a sua autoestima.

A conjugação dos diferentes tipos de educação, uma vez que se complementam, deve-se à perspetiva de que a mesma ocorre ao longo da 
vida. Assim, o indivíduo é "produto” da interação com os pares, havendo, naturalmente, uma evolução dos seus interesses, assim como da sua forma de estar e pensar. Por outro lado, as dinâmicas sociais, nomeadamente ao nível da evolução tecnológica, fazem com que haja uma necessidade constante de atualização das competências adquiridas, de forma sustentável e inclusiva, tal como referido na estratégia Europa 2020 (Machado, 2016).

Contudo, para o desenvolvimento das atividades, são necessárias entidades, públicas e privadas, que ajudem os EP no processo de transformação do indivíduo, para que não ocorra reincidência na reclusão, aquando do seu regresso à sociedade.

A ideia de realizar uma investigação nesta área surge do trabalho desenvolvido com uma população adulta e desperta para a necessidade de qualificação, tanto a nível escolar como profissional, apesar das suas experiências escolares, até à data, terem sido menos positivas. Acresce ainda o facto de se encontrarem em zonas marginalizadas pela sociedade, adquirindo um "rótulo" social difícil de dissociar e na qual sentem que necessitam de uma melhor educação para poderem sonhar com alguma ascensão social. Por último, alguns dos formandos com os quais se trabalhou, já tinham cumprido medidas privativas de liberdade, encontrando-se outros na iminência de as cumprir, o que despertou o interesse em saber o que se passava, ao nível da educação, para estes indivíduos.

Assim, deu-se início ao estudo em três EP do Sistema Judicial de Évora, no âmbito da educação formal e não formal.

\section{DESENVOLVIMENTO}

Para a realização do trabalho referido, assumiu-se a complementaridade de uma análise qualitativa, complementada com uma abordagem quantitativa. Pretendeu-se analisar o fenómeno social, no seu habitat natural, de forma a compreendê-lo, fazendo uma interpretação do mesmo para que seja possível realizar eventuais sugestões de melhoria.

No que se refere ao design da investigação, optou-se pelo estudo de caso múltiplo, uma vez que, assim, seria possível dar uma maior abrangência e consistência à investigação, caso os resultados obtidos fossem convergentes, permitindo, assim, uma maior robustez da mesma.

No período temporal do estudo, considerou-se o ano letivo de 2016/2017. No que se refere ao espaço, a investigação desenrolou-se em três EP do Sistema Judicial de Évora, a saber: EP de Beja, EP de Évora e EP de Odemira. Estes EP foram selecionados considerando a proximidade à Universidade de Évora, a abrangência territorial (Alto e 
Baixo Alentejo), o género dos reclusos (feminino e masculino) e o tipo da população reclusa (civil e forças de segurança).

O trabalho teve início, com uma análise documental, com a finalidade de obter um conhecimento objetivo e atual acerca da oferta de educação em cada EP. Em simultâneo, solicitou-se à Direção Geral de Reinserção e Serviços Prisionais, DGRSP, autorização para realizar a investigação nos EP selecionados. Só, após o aval da DGRSP, foi possível realizar o estudo junto dos estabelecimentos.

Em seguida, foram estabelecidos contactos com os EP, através de correio eletrónico, de forma a solicitar informação sobre o trabalho por eles realizado, sendo assim possível uma confrontação entre a informação enviada pelos EP e a que havia sido recolhida. Deste contacto inicial, os diretores-adjuntos dos EP de Évora e de Odemira mostraram-se disponíveis para uma entrevista exploratória, no sentido de perceber em que consistia o trabalho e qual o apoio que poderiam fornecer para a investigação.

Posteriormente, realizaram-se, novas entrevistas, com os mesmos anfitriões, mas com o objetivo de confirmar a análise prévia. O EP de Beja optou por responder, eletronicamente, às questões colocadas.

\section{RESULTADOS}

Dos EP analisados, verificou-se que as características dos mesmos são bastantes particulares, pelo que, apesar de todos terem preocupação em realizar atividades educativas, de âmbito formal e não formal, as mesmas são distintas, considerando as características singulares dos seus públicos.

Tal como inicialmente perspetivado, de forma transversal a todos os EP, há uma educação formal mais direcionada para a certificação, permitindo elevar os níveis de qualificação escolar e profissional, e uma abordagem não formal que, apesar de organizada e intencional, desenvolve atividades ao nível sociocultural, contemplando uma programação mais direcionada para o bem-estar físico, psíquico e emocional dos indivíduos.

No que à educação formal diz respeito, a principal modalidade promovida é a Educação e Formação de Adultos/EFA, sendo mais significativo a abordagem escolar do que a profissional, devido ao facto de a maioria dos EP não reunir condições para a realização de estágios profissionais. Ocorre também, o processo de Reconhecimento, Validação e Certificação de Competências/RVCC.

Os cursos EFA desenvolvem-se para os níveis B1, B2, B3 e secundário, apesar deste último ser residual. Salienta-se ainda, o facto do EFA B1 apenas se realizar nos estabelecimentos de Beja e Odemira. O nível B1 
refere-se à certificação referente ao $1 .^{\circ}$ ciclo do ensino básico, encontrando-se nestes EP, reclusos sem esta certificação ou a sofrerem de iliteracia funcional.

No que ao ensino superior se refere, apesar da frequência ser menos significativa, esta é maioritariamente ministrada pela Universidade Aberta, uma vez que se trata de uma metodologia de ensino a distância, sendo facilitadora em sujeitos privados de liberdade.

Considerando a educação não formal, esta abrange várias áreas, tais como:

a) a) tipologia específica dos crimes praticados - referindo-se a ações com o objetivo de auxiliar os indivíduos a refletirem sobre os seus comportamentos, compreendendo os aspetos negativos do mesmo, para que os alterem no seu retorno à sociedade;

b) b) leitura - desenvolvem-se parcerias com as bibliotecas municipais, de forma a que seja facultado o acesso a obras, por um tempo mais alargado, visando o desenvolvimento da interpretação, assim como, uma "viagem" através das histórias contadas pelos livros e, dessa forma, "saindo" da prisão;

c) c) sessões de esclarecimento - ações realizadas por voluntários, que visam a alteração de comportamentos de risco, através das explicação das melhores formas de atuação em determinadas situações, nomeadamente a nível da saúde;

d) d) atividade física - além da vertente pessoal, melhorando a saúde e a autoestima, permite, também, desenvolver o relacionamento com os outros, auxiliando a diminuir situações de tensão, inerentes à situação de reclusão;

e) e) outras atividades - existem ainda atividades específicas de cada EP, considerando as características da população prisional. Estas são realizadas, através de parcerias e protocolos estabelecidos entre os EP e entidades locais, do território em que se insere.

Há um problema comum aos EP estudados: a falta de recursos técnicos, humanos e financeiros inviabiliza, por vezes, o desenvolvimento de algumas atividades.

Por último, destaca-se, como aspeto central no processo de ressocialização, a atividade laboral. O foco, no campo profissional, deve-se ao facto desta atividade permitir a (re)aquisição de métodos e hábitos de trabalho, assim como normas de higiene e segurança. A aprendizagem destas competências é importante para que, aquando do retorno à sociedade, os indivíduos sejam competentes e profissionais no desempenho das suas funções, de forma a conseguirem uma atividade profissional que lhes permita obter autonomia financeira, o que é algo fundamental para o desenvolvimento da vida no exterior da prisão. 
A atividade laboral que os reclusos realizam pode ser exercida, tanto no interior como no exterior do EP, dependendo do regime a que o recluso se encontra sujeito. No entanto, carece sempre de autorização por parte do diretor do EP.

\section{DISCUSSÃO}

Os resultados obtidos permitem constatar que os EP apostam na educação, formal e não formal, de forma a ocupar os reclusos, mas também porque compreendem a necessidade de auxiliá-los, na (re)aquisição de competências que poderão ser determinantes no seu processo de ressocialização.

Assim, estes dois tipos de educação convergem no sentido de auxiliar os indivíduos a mudarem comportamentos menos positivos e a tornarem-se mais capacitados para o reingresso na sociedade. Em conjunto, estes dois tipos de educação caminham no sentido de fornecer mais e melhores competências aos reclusos, mas também passa por mantê-los ocupados de forma útil, numa perspetiva de aprendizagem ao longo da vida.

Contudo, o trabalho desenvolvido no interior dos EP apresenta algumas condicionantes, tais como: tempo, espaço, materiais/equipamentos a usar, condições de frequência, interesse dos reclusos e, por último, indivíduos que tenham a formação adequada para desenvolver as diversas atividades.

No sentido de ultrapassar as dificuldades sentidas, a nível financeiro, técnico e humano, os EP estabelecem parcerias e "aproveitam” instituições que, através de voluntários, desenvolvem atividades com os reclusos.

Na globalidade, da análise documental e do contacto com os EP, pode concluir-se que a educação nos mesmos assume um lugar de destaque, pela sua importância no processo de ressocialização. Contudo, esta tem de ser diversificada e abrangente, de forma a proporcionar um bem-estar geral ao indivíduo, dentro das limitações inerentes ao sistema de reclusão. No entanto, a educação ainda é considerada como ocupação, visando a diminuição de conflitos inerentes à situação de reclusão e, ainda, não tanto como um direito/necessidade que poderá dotar o recluso de competências que o irão auxiliar, quando em liberdade, a construir o seu caminho de forma autónoma, construtiva e sem recaídas.

Deverá ainda referir-se o facto de os reclusos necessitarem de motivação extra para desempenhar algumas atividades. Há que ter consciência que as recordações referentes à escola, por parte dos reclusos, nem sempre são positivas, sendo necessário que os formadores auxiliem neste processo, de forma a evitar o abandono escolar. Neste sentido, é necessário que os próprios formadores tenham formação específica 
para lidar com as particularidades dos reclusos, algo que nem sempre acontece.

Assim, além do trabalho desenvolvido poder contribuir para uma análise da situação atual dos EP, pretende-se também ajudar a refletir sobre novas formas de educação neste meio que possam ser mais atuais e significativas para auxiliar o retorno dos indivíduos na sociedade, nomeadamente no que se refere às novas tecnologias, perspetivando assim uma educação ao longo da vida, tal como referido em Machado (2016).

\section{CONSIDERAÇÕES FINAIS}

A educação é fundamental para todos os cidadãos, sendo também um direito consagrado universalmente. Revestindo-se de particular importância na população reclusa, visto que permite a (re)aquisição de regras para a salutar convivência entre todos os cidadãos, além de, no âmbito formal, aumentar o nível de qualificação escolar e profissional, o que irá ajudar a ressocialização destes indivíduos.

Considerando o tempo disponível que os reclusos têm, em privação de liberdade, este deve ser ocupado de forma útil, mas não apenas numa perspetiva de combater o ócio e evitar os conflitos no interior da prisão.

Assim, o tempo de reclusão deverá ser usado para que os reclusos possam refletir nas suas atitudes menos corretas, de forma a alterá-las. Por outro lado, através da participação em processos educativos os reclusos podem melhorar as suas competências de forma a valorizarem a imagem de si próprios, aumentando a sua autoestima, melhorando a relação com os outros e adquirindo saber para desempenhar atividades profissionais.

A educação, assim como as restantes atividades desenvolvidas nos EP, deve ter uma visão ampla, permitindo ao indivíduo desenvolver-se integralmente, de forma a adquirir competências em áreas tão distintas e específicas como, saúde, ambiente, tecnologia. Contudo, ainda há a necessidade de aprofundar o investimento em todas as áreas referidas, destacando as tecnologias de informação e comunicação.

Considerando a atualidade, o uso das tecnologias assume um papel central no desenvolvimento das sociedades. A Era digital implica que todos tenham conhecimento tecnológico, onde aqueles que não o possuem se encontrem menos aptos para enfrentar o mundo. Neste sentido a reclusão, terá de ser capaz de dar uma resposta para colmatar esta lacuna, algo que também já se encontra a ser testado.

Por último, não se pode descurar o facto de estes indivíduos terem uma "bagagem" pessoal, que tem de ser considerada, para que o processo educativo possa ser bem sucedido. Assim, os seus interesses individuais 
têm de ser contemplados, de forma a permitir que o seu conhecimento seja sustentado e sustentável, que a sua atitude seja critica e que a sua reflexão permita uma visão de futuro, de forma a que consigam ser melhores cidadãos, no futuro. No entanto, para que tudo isto se consiga é necessário a motivação e "abertura” dos reclusos para a aprendizagem e mudança.

\section{REFERÊNCIAS BIBLIOGRÁFICAS}

Gomes, I. (2008). Da Prisão à Liberdade: Reinserção Social de Ex-Reclusos (Dissertação de Mestrado). Instituto Superior de Ciências do Trabalho e da Empresa, Lisboa. Recuperado de http://hdl.handle.net/10071/1366

Julião, E., Onofre, E. (2013, janeiro-março). Educação em Prisões. Revista Educação \& Realidade, 38(1), 11-14. Recuperado de http://dx.doi. org/10.1590/S2175-62362013000100002

Machado, A. (2016). Educação à Distância e E-Learning no Ensino Superior em Contexto de Reclusão. Um Estudo de Caso no Estabelecimento Prisional do Porto (Dissertação de Mestrado). Universidade Aberta. Recuperado de http://hdl.handle.net/10400.2/6604

Meirinhos M., Osório A. (2010). O estudo de caso como estratégia de investigação em educação. EDUSER - Revista de Educação, 2(2), 49-65. Recuperado de https://www.eduser.ipb.pt/index.php/eduser/article/view/24

PORDATA. (2009). Indicadores de Reclusos: total e por nível de instrução completo em Portugal. PORDATA - Estatísticas, gráficos e indicadores de Municipios, Portugal e Europa. Recuperado de https://www.pordata. pt/Portugal/Reclusos

Rangel, H. (2007,janeiro-abril). Estratégias sociais e educação prisional na Europa: visão de conjunto e reflexões. Revista Brasileira da Educação,81-93. Recuperado de http://www.scielo.br/pdf/rbedu/v12n34/ a07v1234.pdf 